\title{
Contribution of Low-carbon Transport Policy to the Improvement of Urban Traffic Ecological Environment
}

\author{
Mingwei Li and Huijuan Zhao \\ College of Tourism, Xinyang Normal University, Xinyang, Henan, 464000, China \\ †Corresponding author: Mingwei Li; limingwei_happy@163.com
}

\section{Nat. Env. \& Poll. Tech. \\ Website: www.neptjournal.com \\ Received: $12-09-2020$ \\ Revised: 27-10-2020 \\ Accepted: 07-12-2020 \\ Key Words: \\ Low-carbon transport \\ Ecological environment \\ Urban traffic \\ Urbanization}

\begin{abstract}
With the acceleration of urbanization and motorization speed boost, the development of urban green traffic has become a focus of public concern and an important way to solve urban traffic problems, which has made the low-carbon transport policy been given more attention. However, since the urban traffic is affected by multiple factors, whether the application of low-carbon transport policy could obtain corresponding or higher output is uncertain. To clarify the effects of low-carbon transport to the improvement of urban traffic ecological environment, the main indicators that measure the contribution of low-carbon transport to urban traffic ecological environment were extracted from five aspects including people, cars, roads, transportation infrastructure and traffic environment. The Guangzhou city in China was taken as an example to select index data, the regression analysis was adopted by SPSS software. Results show that the contribution rate of the low-carbon transport policy to the improvement of urban transportation ecological environment is $4.42 \%$. The conclusions obtained from this study are of great significance to improve the low-carbon travel policy and optimize the urban traffic ecological environment
\end{abstract}

\section{INTRODUCTION}

Transportation energy and emission reduction policy is a set of governmental regulation means to cope with global climate change and to alleviate the pressure of transportation energy consumption under the background of the low-carbon economy. Low-carbon transport first appeared in official documents in the UK in May 2007, the United Kingdom initially put forward the "Low-Carbon Transport Innovation Strategy", and it also released "Low Carbon Transport: A Greener Future" in July 2009. Besides, in work arrangements to deal with climate change, China has made it clear that to speed up the construction of industrial construction and transportation systems characterized by low carbon emissions.

Currently, there is no clear and agreed definition for lowcarbon transport. This study defines low-carbon transport in two aspects. Firstly, we focus on the characteristics of low-carbon. It is a kind of transportation development mode characterized by low energy consumption, low emission, and low pollution, which devotes itself to improve the energy efficiency and energy structure of transportation and slow down the carbon emission of transportation. The aim is to make the transportation system gradually get rid of the excessive dependence on fossil energy, realize the lowcarbon transformation development. Secondly, focusing on transport demand satisfaction, low-carbon transport is a new industrial form that cannot only meet the normal needs of economic and social development but also reduce the carbon intensity of transport volume. That is to say, low-carbon transport is a new industrial development mode with the lowest carbon intensity (or the highest carbon productivity) and the maximum utility achieved. Low-carbon transport is a development revolution. Its basic connotation is embodied in the characteristics of "three low" and "three high". They are low consumption, low emission, low pollution, high energy efficiency, high efficiency, and high benefit. Besides, the transportation energy conservation and emission reduction policies are also for "three low, three high". To standardize and guide the low-carbon transport development through government means.

By December 2019, China's car ownership per capita has reached the global average ( 11 cars per 65 people, 0.17 cars per capita) from the current "70 cars per 1,000 people" (0.07 cars per capita). With the rapid increase of per capita car ownership, related issues such as vehicle energy conservation and emission reduction have become the focus of the government (Jiang et al. 2008). During the 13th Five-Year Plan period, the Chinese government launched the "urban public transport" demonstration project, which aims to ensure that the mode of public transport travel could be improved continuously with the strong support of local governments. It is expected that the share rate of public transport in cities 
with rail transit will reach more than $60 \%$ by the end of the 13th Five-Year Plan period. Besides, an efficient public transport network will be formed to reduce the pressure and emissions of the urban transport operation, and continue to move closer to the direction of building low-carbon transport (Liu 2012, Li 2017). However, as one of the important means of transportation for urban development, private cars cannot be restricted by blindly developing public transport to ensure the normal development of the city. Therefore, based on the low-carbon transport policy, this study excavates its main factors in promoting the development of urban traffic ecological environment, clarifies its role in the whole process and promotes the development of urban traffic ecological environment are the current situation needs to solve.

This study evaluates the contribution value of low-carbon transport policy to the development of urban traffic ecological environment, which does not only help to clarify the relationship and the main indicators. It can also put forward strategies and suggestions for the development of urban traffic ecological environment according to the research results of the contribution rate and promote healthy and sustainable development strategies for urban traffic.

\section{PAST WORK}

In terms of the researches collected in this study, relative researches have been obtained on low carbon travel and transportation ecological environment. For example, developed countries in Europe and the United States have studied low-carbon transport for nearly 50 years. In this process, with the city scale, motor vehicle intelligence, and other factors, scholars have also put forward different research strategies in this field. Jess (1999) believed that zero emissions and less land cover are in line with the basic principles of urban low-carbon transport development. In addition, some scholars believe that transportation infrastructure and road planning have a greater impact on public transportation, and some cities in Europe and American are selected as the research objects to carry on the demonstration analysis. The results show there is not only a mutual interaction between travel time and price also affects the choice of travel mode and travel comfort, which will result in a low rate of ecological travel (Ryuichi 2009).

Scheiner (2010) used various mathematical models to evaluate the development of low-carbon transport in cities of different countries. The results show that the development of low-carbon transport has a certain impact on the traffic ecological environment. However, their findings are only qualitative results and there is no in-depth analysis of the specific impact from the quantitative point of view. Geenhuizen et al. (2003), Kahn (2006), Svensson et al. (2010) concluded that low-carbon transport is the first choice for the development of ecological traffic. However, they put forward that it does not meet the requirements of traffic network development just based on the infrastructure construction, while the deep integration of sustainable transportation policy is imperative when developing the ecological traffic. Du et al. (2006), Jiang et al. (2008), Li et al. (2015) established different evaluation systems for the development of low-carbon transport from the perspective of sustainable development to discuss the relationship between sustainable development of urban traffic and ecological traffic. Yu et al. (2008) proposed that there is a competitive relationship between public transport and private transport by using operational research and econometric models to study the effects of low-carbon travel on the development of ecological traffic. It is considered that the effect of low-carbon transport on the traffic ecological environment is relatively perfect when the competitive relationship reaches a dynamic equilibrium state. Zeng et al. (2007) chose the Logit model to study the public transport problem, but more researches are to predict the development trend of public transport and the possible problems, while the impact of public transport on the development of ecological transport is less involved. Sun (2010) studied low-carbon transport based on the analysis of affecting factors and indicators by combining the mathematics and operational research methods research. Then the empirical analysis was carried out by collecting the data of the indicators and the countermeasures were put forward. According to the literature review, the relationship between low-carbon transport and transportation ecological environment has become the main attention of society and academia and has achieved certain results. However, the early discussions on the urban traffic-operating environment were limited to the problems faced by traffic development, such as traffic congestion, traffic safety, and so on. Afterwards, the related problems about the development of urban ecological traffic were studied with the increasingly serious traffic environment problems. Moreover, the existing results have separated the low-carbon travel and the ecological traffic, which cannot analyze the low-carbon travel and ecological traffic as related completely effectively. Therefore, the research on the interaction between the two needs to be strengthened, and the quantitative research from the perspective of contribution rate needs to be further deepened.

\section{MATERIALS AND METHODS}

\section{Construction of the Index System}

It can be seen that scholars have done some researches on the indicators of urban ecological traffic development and a partial index system has formed from the results of the 


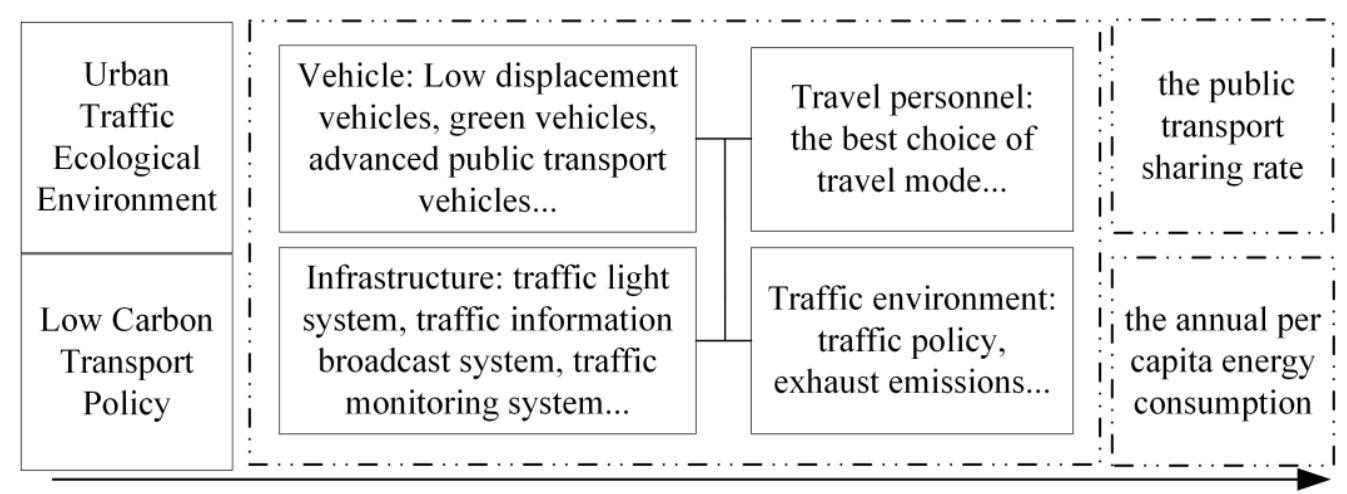

Fig. 1: Extraction path of the indexes.

literature analysis. Based on referring to the existing research results, considering the development of urban ecological traffic and the ecological environment requirements of low-carbon transport policies, we analysed and extracted indicators that can measure the ecological environment of urban traffic from five aspects. They are the travel personnel, vehicles, roads, transport infrastructure, and traffic operation environment. According to the index system, combined with the requirements and characteristics of low-carbon transport policies, the indicators were screened. Finally, it was considered that the public transport sharing rate and annual per capita energy consumption could be used to measure the ecological environment of transportation (Zhou et al. 2011). The specific index extraction path is shown in Fig. 1.

\section{Index Interpretation}

It was found that the index data cannot be directly collected, nor can the indicators be directly processed by the model when we processing the indexes. Instead, the influencing factors of each indicator should be extracted through certain procedures. The final influencing factors of the indicators should be determined through data collection, data processing and other operations on the influencing factors. Because the factors that affect the development of ecological traffic are related to each other, there will be a phenomenon of cross-influencing factors when analysing the influencing factors of each index. Therefore, when extracting the influencing factors of the index, we should start from five aspects of travel personnel, vehicles, roads, and infrastructure and traffic environment reference to the extracting method of the ecological traffic development indicators.

Public transport sharing rate: The public transport-sharing rate refers to the proportion of public transportation (including conventional public transport, rapid public transport and rail transit, excluding taxis, buses, school buses) in the total travel volume of urban residents who choose public transport in their travel modes. This index is an important factor to promote the development of public transport and the rational structure of urban traffic. Besides, it is also one of the core indicators of urban ecological traffic evaluation. The Ministry of Construction and the Ministry of Public Security of China have stipulated in the "Green Traffic Model City Assessment Standard (2003)" that the public transport-sharing rate should not be less than $20 \%$ in large cities and $15 \%$ in medium cities. Furthermore, the International Association of Public Transport has put forward the standards for public transport sharing rate in the year 2001 (Pekka et al. 2002) as given in Table 1.

Table 1: International standard of the public transport sharing rate.

\begin{tabular}{|llllll|}
\hline City & $\begin{array}{l}\text { Public transport sharing } \\
\text { rate }(\%)\end{array}$ & City & $\begin{array}{l}\text { Public transport sharing } \\
\text { rate }(\%)\end{array}$ & City & $\begin{array}{l}\text { Public transport sharing } \\
\text { rate }(\%)\end{array}$ \\
\hline Amsterdam & 66.1 & Copenhagen & 51.1 & Medellin & 95 \\
Barcelona & 53.1 & Glatz & 53.6 & Munich & 59.4 \\
Berlin & 60.8 & Helsinki & 56 & Paris & 53.6 \\
Berne & 59.7 & Hong Kong & 83.8 & Rio de Janeiro & 85 \\
Bogota & 85 & Lima & 84 & Salvador & 86 \\
Budapest & 66.9 & Lisbon & 52 & Vienna & 64 \\
Curitiba & 71 & Moscow & 73.7 & Warsaw & 71.4 \\
\hline
\end{tabular}


It found that travel personnel, vehicles, roads and traffic environment mainly affect the public transport-sharing rate according to the definition and evaluation criteria. In terms of the impact of travel personnel, the number of people who choose public transport determines the public transport-sharing rate to a certain extent immediately. The larger the proportion of public transport travel, the greater the sharing rate of public transport will be. However, to improve the number of people who choose public transport, it is necessary to provide enough public transport to meet the travel needs of travellers, which is a challenge to the local government. At the same time, there must be special roads and lanes for public transport to ensure safety, comfort and convenience. Only in this way can more people choose public transport to travel. In terms of traffic environmental impact, the impact on public transport sharing rate is mainly reflected in relevant policies, such as the low-carbon transport policy. For example, the restriction policy implemented by the traffic management department, the policy that external vehicles are not allowed entering the inner ring of the city for a limited period. Based on the above analysis, this study puts forward the calculation formula of public transport sharing rate.

$$
f_{1}=n_{1} / N_{1}
$$

In formula (1), $f_{1}$ represents the public transport sharing rate, $n_{1}$ represents the travel volume of public transport travel (unit: 10,000 person-times), and $N_{1}$ represents the total urban travel volume (unit: 10,000 person-times).

Annual per capita energy consumption: The transportation industry has always been regarded as one of the important fields of social carbon emissions and energy consumption. How to reduce the energy consumption and carbon emissions of the transportation industry is being explored all over the world. In the past decade, China has made more breakthroughs and progress in the field of traffic energy conservation and emission reduction. For example, a large number of laws, plans, standards and norms related to energy conservation and emission reduction have been issued, providing important guidance for the development of energy conservation and emission reduction. A large number of energy conservation and emission reduction technologies and products have been popularized and applied, which effectively improves the production efficiency and service level of transportation, enhances the technical foundation and support capacity of transport energy conservation and emission reduction, and saves a lot of energy. Among them, the calculation formula of urban traffic energy consumption constraint is as follows.

$$
C_{\text {Energy }}=\sum_{j=1}^{n}\left(e_{j} \times X_{j}\right)(\mathrm{MJ})
$$

Where, $C_{\text {Energy }}$ is the urban energy consumption of urban energy transportation, $e_{j}$ is the energy consumption factor of the $j$ transportation mode, and $X_{j}$ is the passenger turnover of the $j$ transportation mode. Table 2 gives the values under different transportation modes.

According to the relevant research results and the above analysis, the calculation method of annual per capita travel energy consumption is as follows.

$$
F_{1}=m_{1} / M_{1}
$$

In formula (3), $F_{1}$ represents the annual per capita energy consumption, $m_{1}$ represents the total transportation energy consumption (unit: 10,000 tons of coal) and $M_{1}$ represents

Table 2: Energy consumption factors of different transportation modes.

\begin{tabular}{|lllllll|}
\hline Transportation modes & Private car & Bus & Taxi & Rail transit & Bicycle & On foot \\
\hline$e_{j}(\mathbf{M J} /$ per $\mathbf{k m})$ & 2.3 & 0.3 & 2.4 & 0.1 & 0 & 0 \\
\hline
\end{tabular}

Table 3: The summary table of index influencing factors.

\begin{tabular}{|l|l|}
\hline Index & Influencing factors \\
\hline Public transport sharing rate & Public vehicle ownership per 10,000 \\
& Average daily passengers of public transport \\
& Per capita GDP \\
& Per capita road area \\
& Total urban travel: (total urban population multiply per capita daily travel times) \\
& Passenger volume of public transport \\
& Number of public transport vehicles \\
Annual per capita energy consumption & Total number of motor vehicles in the city \\
& Number of civil motor vehicles in the city \\
& Total fuel consumption for passenger transport \\
& Total social passenger volume \\
Per capita GDP & Per capita road mileage \\
\hline
\end{tabular}


the total urban travel (unit: 10,000 person-times).

According to formula (3), under the condition that the total amount of urban travel remains unchanged, the more fuel consumed by passenger vehicles, the worse the effect of ecological traffic development, and vice versa. Therefore, the index is mainly controlled by the total fuel consumption and population turnover, while the number of motor vehicles, road conditions and motor vehicle emissions affects the total fuel consumption and the population turnover is the total number of people turnover per unit time.

To sum up, the influencing factors of these two indicators are summarized as follows, as shown in Table 3.

Function expression of the index: Before analysing the functional relationship between the traffic ecological environment index and its influencing factors, the functional relationship of the index to measure the traffic ecological environment is first analysed. The functional relationship between ecological traffic and its indicators is as follows.

$$
\begin{gathered}
Y_{G}=F\left\{f_{1}\left(x_{11}, x_{12}\right), f_{2}\left(x_{21}, x_{22}, x_{23}\right),\right. \\
\left.f_{3}\left(x_{31}, x_{32}, x_{33}\right), f_{4}\left(x_{41}, x_{42}, x_{43}\right), f_{5}\left(x_{51}, x_{52}\right)\right\}
\end{gathered}
$$

Where, $Y_{G}$ represents the traffic ecological environment index, $f_{1}, f_{2}, f_{3}, f_{4}, f_{5}$ respectively represents the five aspects of the impact factors: travel personnel, vehicles, roads, infrastructure and traffic environment.

$x_{11}$ represents the environmental awareness travel personnel, $x_{12}$ represents the travel structure of travel personnel.

$x_{21}$ represents the amount of vehicle ownership, $x_{22}$ represents the vehicle emissions, $x_{23}$ represents the vehicle institutions.

$x_{31}$ represents the road network structure, $x_{32}$ represents the per capita road area, $x_{33}$ represents the public transport dedicated lane.

$x_{41}$ represents the rationality of the traffic lights, $x_{42}$ represents the rationality of the traffic signs, $x_{13}$ represents the rationality of the public transport stations.

$x_{51}$ represents the natural environment, $x_{52}$ represents the relevant policies.

In analysing the functional relationship between each index and its influencing factors, the specific method is similar to the above. In this case, it is necessary to regard each index as a dependent variable and the corresponding influencing factor as an independent variable. The specific formula is as follows.

$$
Y_{G 1}=F_{1}\left(y_{11}, y_{12}, y_{13}, y_{14}\right)
$$

Among them, $Y_{G 1}$ represents the index of the public transport-sharing rate, $y_{11}$ represents the public vehicle ownership per 10,000 people, $y_{12}$ represents the average daily passenger number of public transport, $y_{13}$ represents the per capita GDP, $y_{14}$ represents the road area per capita.

$$
Y_{G 2}=F_{2}\left(y_{21}, y_{22}, y_{23}, y_{24}, y_{25}\right)
$$

Where $Y_{G 2}$ represents the annual per capita energy consumption, $y_{21}$ represents the total number of motor vehicles, $y_{22}$ represents the number of other motor vehicles (vehicle ownership per capita), $y_{23}$ represents the total energy consumption of passenger transport, $y_{24}$ represents the total number of urban passenger transport, $y_{25}$ represents the per capita GDP.

The quantitative function is reflected in the influencing process of the traffic ecological environment. When analysing the influence of a certain factor on the index, other factors must be assumed unchanged. Only in this way can be calculated the impact of a single factor on the analysis index accurately. Regression analysis can be used to find and reduce the correlation between the various influencing factors, to maintain the direct and independent effects of the influencing factors on ecological traffic.

\section{Data Source}

This study takes Guangzhou city in China as an example to collect data and analyze the contribution of the low-carbon transport policy to ecological traffic development. The reason for choosing Guangzhou is that: first, Guangzhou is in the critical period of the rapid development of urbanization and motorization. How to improve the traffic environment in Guangzhou has become a hot issue for the government and citizens. Second, the application of low-carbon transport policy in Guangzhou is in the leading position in China, and it has made certain achievements. With the rapid development of modernization, urbanization, and motorization, it has become an inevitable choice to solve the urban traffic problems in Guangzhou.

The data are collected from the year 2000 to 2015 of the Guangzhou Economic and Social Development Statistics Bulletin, the Statistical Yearbook of Guangzhou, and the Guangzhou Transportation Yearbook.

\section{RESULTS ANALYSIS}

\section{Contribution of the Public Transport-Sharing Rate}

The SPSS 22.0 software is used to analyze the data of influencing factors of public transport sharing rate. We chose the public vehicle ownership per 10,000 people, average daily passengers of public transport, the per capita GDP, per capita road area, total urban travel, passenger volume of public transport and umber of public transport vehicle as independent variables, and the public transport-sharing rate 
Table 4: Models.

\begin{tabular}{|lllll|}
\hline Model & $\mathrm{R}$ & $\mathrm{R} 2$ & Modified $\mathrm{R}^{2}$ & $\begin{array}{l}\text { Error in standard } \\
\text { estimates }\end{array}$ \\
\hline 1 & 0.961 & 0.924 & 0.915 & 0.013096 \\
2 & 0.999 & 0.998 & 0.997 & 0.002475 \\
\hline
\end{tabular}

as dependent variables. Then the multiple linear regression analysis was carried out (Table 4).

The regression equation is better according to the value of $\mathrm{R}, \mathrm{R}^{2}$ and modified $\mathrm{R}^{2}$. For regression analysis, the input variables are the average daily passengers of public transport and the per capita GDP. Other variables are removed and the results are shown in Table 5.

By analysing the input variables, the final coefficient table is shown in Table 5, where the $\operatorname{Sig}=0$, which indicates that the obtained coefficients meet the regression requirements, then the following equation can be obtained.

$$
Y_{G 1}=0.037+0.061 y_{12}-0.007 y_{13}
$$

In calculating the contribution rate of Guangzhou's low-carbon transport policy to urban traffic ecological environment, the data from 2000-2014 are mainly collected. Because in 2014, the Guangzhou Energy Research Institute of the Chinese Academy of Sciences led the organization of Guangzhou Traffic Planning Research Institute, Guangzhou Institute of Architectural Sciences Co. Ltd., Guangzhou carbon emission rights exchange jointly launched the Guangzhou National low carbon pilot Project (Wang et al. 2018). That is, this study put forward that the low carbon transportation policy of Guangzhou has been implemented since 2014, so it is considered that the data before 2014 are not affected by the low carbon transportation policy. Therefore, taking the data from 2000 to 2014 as an example to do regression analysis, and the public transport-sharing rate in 2015 is estimated according to the regression equation.
While the public transport-sharing rate in 2015 can be known in the actual statistics yearbook of Guangzhou, then the actual value is subtracted from the predicted value, and the obtained value can be considered as the contribution of low-carbon transport policy. It should be noted that in calculating the contribution of low-carbon transport policies, the impact of other policy factors is not taken into account, but these policy factors are default to the impact of low-carbon transport policies. Finally, the contribution of low-carbon transport policy to the public transport-sharing rate is obtained as follows.

$$
\begin{aligned}
Y_{G 1(2015 \text { predicted value })} & =0.037+0.061 y_{12}-0.007 y_{13} \\
= & 0.037+0.061 * 6.927-0.007 * 9.957=0.392 \\
Y_{G 1(2015 \text { actual value })} & =0.0387
\end{aligned} .
$$

The contribution value is that

$$
\begin{aligned}
E_{1} & =\left(Y_{G 1(2015 \text { predicted value })}-Y_{G 1(2015 \text { actual value })}\right) / Y_{G 1(2015 \text { actual value })} \\
& =(0.392-0.387) / 0.387 \\
& =1.3 \%
\end{aligned}
$$

\section{Contribution of the Annual Per Capita Energy Consumption}

SPSS 22.0 software is used to analyze the data of influencing factors of public transport sharing rate. We chose the total number of motor vehicles in the city, the number of civil motor vehicles in the city, total fuel consumption for passenger transport, total social passenger volume, per capita GDP and per capita road mileage as dependent variables, and the annual per capita energy consumption as dependent

\begin{tabular}{|c|c|c|c|c|c|c|}
\hline \multicolumn{2}{|c|}{ Model } & \multicolumn{2}{|c|}{ Non-standardized coefficient } & \multirow[t]{2}{*}{ Standardized coefficient } & \multirow[t]{2}{*}{$\mathrm{t}$} & \multirow[t]{2}{*}{ Sig. } \\
\hline & & $\mathrm{B}$ & Standard error & & & \\
\hline \multirow[t]{2}{*}{1} & constant & 0.071 & 0.027 & & 2.646 & 0.027 \\
\hline & average daily passengers of public transport & 0.048 & 0.005 & 0.961 & 10.448 & 0.000 \\
\hline \multirow[t]{3}{*}{2} & constant & 0.037 & 0.006 & & 6.739 & 0.000 \\
\hline & average daily passengers of public transport & 0.061 & 0.001 & 1.215 & 51.064 & 0.000 \\
\hline & per capita GDP & -0.007 & 0.000 & -0.371 & -15.617 & 0.000 \\
\hline
\end{tabular}
variables. Then the multiple linear regression analysis was carried out (Table 6).

The regression equation is better according to the value of $\mathrm{R}, \mathrm{R}^{2}$ and modified $\mathrm{R}^{2}$. For regression analysis, the input variable is the number of civil motor vehicles in the city.

Table 5: Coefficient.

Table 6: The model.

\begin{tabular}{|lllll|}
\hline Model & $\mathrm{R}$ & $\mathrm{R}_{2}$ & Modified $\mathrm{R}^{2}$ & Error in standard estimates \\
\hline 1 & 0.839 & 0.704 & 0.672 & 0.001210 \\
\hline
\end{tabular}


Table 7: Coefficient.

\begin{tabular}{|c|c|c|c|c|c|c|}
\hline \multirow{2}{*}{\multicolumn{2}{|c|}{ Model }} & \multicolumn{2}{|c|}{ Non-standardized coefficient } & \multirow[t]{2}{*}{ Standardized coefficient } & \multirow[t]{2}{*}{$\mathrm{t}$} & \multirow[t]{2}{*}{ Sig. } \\
\hline & & $\mathrm{B}$ & Standard error & & & \\
\hline \multirow[t]{2}{*}{1} & constant & 0.034 & 0.004 & & 7.230 & 0.000 \\
\hline & number of civil motor vehicles in the city & -0.086 & 0.019 & -0.839 & -4.631 & 0.001 \\
\hline
\end{tabular}

Other variables are removed as shown in Table 7.

Then the following regression equation can be obtained.

$$
Y_{G 2}=0.034-0.086 y_{22}
$$

Finally, the contribution of low-carbon transport policy to the annual per capita energy consumption obtained as follows.

$$
\begin{aligned}
E_{2} & =\left(Y_{G 2(2015 \text { predicted value })}-Y_{G 2(2015 \text { actual value })}\right) / Y_{G 2(2015 \text { actual value })} \\
& =(0.00949-0.009) / 0.009 \\
& =5.4 \%
\end{aligned}
$$

The contribution value is that

$$
\begin{aligned}
E_{2} & =\left(Y_{G 2(2015 \text { predicted value })}-Y_{G 2(2015 \text { actual value })}\right) / Y_{G 2(2015 \text { actual value })} \\
& =(0.00949-0.009) / 0.009 \\
& =5.4 \%
\end{aligned}
$$

Wang et al. (2018) pointed out that the implementation strategy of urban traffic carbon emission reduction is focused on three aspects: avoidance, transfer and improvement. The avoidance strategy refers to avoiding unnecessary traffic demand from the source through reasonable urban spatial form and diversified land use. It mainly includes reducing travel times, shortening travel distance and so on, thus reducing traffic carbon emissions. The transfer strategy refers to the adjustment of traffic structure and the conversion of passengers who rely partly on private motorized transportation to green travel mode, including public transport, bicycle and walking traffic. The improvement strategy is aimed at the improvement of vehicle energy efficiency, which is essentially the research and application of low-carbon vehicles. The research results show that the transfer of urban public transport travel mode has the greatest emission reduction potential. Guangzhou is in the rapid construction stage of rail transit; the public transport service level will be greatly improved. Therefore, the main carbon reduction potential at this stage mainly comes from the mode transfer. While the carbon reduction effects of the traffic demand reduction strategy brought by urban planning are relatively lagging. According to statistics, the reduction in carbon emissions by public transport share in Guangzhou is accounted for 24 percent and the capita energy consumption occupied 76 percent. Therefore, when calculating the contribution of low-carbon policy to the development of urban ecological traffic, this study calculates the contribution rate mainly adopts the following formula.

$$
E=0.24 Y_{G 1}+0.76 Y_{G 2}=0.24 * 1.3 \%+0.76 * 5.4 \%=4.42 \%
$$

That is, the contribution rate of low-carbon policy to the development of ecological traffic in Guangzhou is $4.42 \%$.

\section{CONCLUSIONS}

The effects of low-carbon transport to the improvement of urban traffic ecological environment were explored in this study, the conclusions are as follows: the contribution rate of the low-carbon transport policy in Guangzhou of China to the improvement of urban transportation ecological environment is $4.42 \%$. Low-carbon policy plays a great role in alleviating the improvement of urban traffic ecological environment. It can promote the priority development of public transport, optimize the travel structure and improve the green travel rate, slow down traffic congestion and reduce the driving time and distance of vehicles. Although low-carbon policies can improve the ecological environment of urban traffic, the urban traffic environment is becoming worse and worse with the increasing number of motor vehicles in major cities. While more practical actions should be carried out than the effects of low-carbon policy to improve the ecological level of urban traffic operation services.

\section{ACKNOWLEDGMENT}

This study was supported by the Humanity and Social Science Youth Foundation of the Ministry of Education of China (No. 19YJCZH082), the Science and Technology Project of Henan Province (No. 212400410259), and the Nanhu Scholars Program for Young Scholars of XYNU (No. 2017B).

\section{REFERENCES}

Du, S.P., Xiong, L. and Ding, W. D. 2006. Comprehensive evaluation of urban rail transit network planning based on green transportation principle. Journal of Southwest Jiaotong University, 41(3): 284-289.

Geenhuizen, M.V., Geerlings, H. and Priemus, H. 2003. Transport innovation: coping with the future. Transportation Planning \& Technology, 26(6): 437-447.

Jesse, H. Ausubel. 1999. Reasons to worry about the human environment. Technology in Society, 13: 230-254.

Jiang, Y.H., He, X.Z. and Guo, X.C. 2008. Discussion on the evaluation 
index system of urban green traffic planning. Journal of Hefei University of Technology (Nature Science), 31(9): 1399-1402.

Kahn, M.E. 2006. The Environmental Impact of Suburbanization. Journal of Policy Analysis and Management, 19: 569-586.

Li, M.W. 2017. Research on the Mode and Suggestion of "Internet+ Transportation" Fusion Development. Journal of Xinyang Normal University (Philosophy and Social Sciences Edition), 37(1): 61-65.

Liu, H.D. 2012. Public transportation share ratio forecasting based on box-cox dogit model. journal of transport information and safety, 30(1): 47-51.

Pekka, L.K. and Jukka, L. 2002. Profitability evaluation of intelligent transport system investments. Journal of Transportation Engineering, 128(3): 276-286.

Ryuichi, K.A. 2009. Dynamic model system of household car ownership, trip generation, and modal split: model development and simulation experiment. Transportation, 36(6): 711-732.

Scheiner, J. 2010. Social inequalities in travel behavior: trip distances in the context of residential self-selection and lifestyles. Journal of Transport Geography, 18(6): 679-690.
Sun, X.Q. 2010. The coordinated development of urban traffic and integrated transport hub. Science \& Technology Information, (11): 105-115.

Svensson, M. and Johansson, M. V. 2010. Willingness to pay for private and public road safety in stated preference studies: Why the difference. Accident Analysis \& Prevention, 42(4): 1205-1212.

Wang, B. and Zhang, H.X. 2018. Development strategies of low carbon transportation in Guangzhou. Urban Transport of China, 16(4): 74-80.

Yu, L.J. and Heydecker, B. 2008. Statistical distribution estimation method for traffic flow using probability weighted moments and maximum entropy principle. Journal of Highway and Transportation Research and Development, 2(25): 113-116.

Zeng, X. and Wang, C.G. 2007. Improvement of logit model and its application in forecasting the distribution rations of passenger flows on Cheng-Yu intercity railroad. Journal of Changsha Communications University, 4(23): 50-53.

Zhou, X.M. and Di, D. 2011. Urban passenger transportation terminal location based on bus-sharing ratio. Journal of Tongii University (Natural Science), 39(9): 1313-1317. 